\title{
Marrow adipocytes inhibit the differentiation of mesenchymal stem cells into osteoblasts via suppressing BMP-signaling
}

Basem M. Abdallah ${ }^{1,2,3}$

\begin{abstract}
Background: Reduced bone formation is associated with increased bone marrow fat in many bone-loss related diseases including aging, post-menopause, and anorexia nervosa. Several lines of evidence suggested the regulation of osteogenesis and adipogenesis of the bone marrow-derived mesenchymal (skeletal) stem cells (BMSCs) by paracrine mediators. This study aimed to investigate the impact of adipocytes-secreted factors on the cell proliferation and osteoblast differentiation of BMSCs.

Methods: Serum free conditioned medium (CM-Adipo) was collected from stromal ST2 cells-derived adipocytes. Cell viability, quantitative alkaline phosphatase (ALP) activity assay, Alizarin red staining for matrix mineralization and osteogenic gene array expression were performed to determine the effect of CM-Adipo on cell proliferation and osteoblast differentiation of primary murine BMSCs (mBMSCs). Regulation of BMPs and NF-kB signaling pathways by CM-Adipo were detected by Western blot analysis and gene reporter assay.

Results: CM-Adipo showed no effect on cell viability/proliferation of primary mBMSCs as compared to CM-control. On the other hand, CM-Adipo significantly inhibited the commitment of mBMSCs into osteoblastic cell lineage in dose-dependent manner. CM-Adipo was found to dramatically inhibit the BMP2-induced osteoblast differentiation and to activate the inflammatory NF-kB signaling in mBMSCs. Interestingly, treatment of mBMSCs with the selective inhibitor of NF-KB pathway, BAY11-770682, showed to retrieve the inhibitory effect of CM-Adipo on BMP2-induced osteoblast differentiation in mBMSCs.

Conclusions: Our data demonstrated that the marrow adipocytes exert paracrine inhibitory effect on the osteoblast differentiation of mBMSCs by blocking BMPs signaling in a mechanism mediated by adipokines-induced NF-KB pathway activation.
\end{abstract}

Keywords: Mesenchymal stem cells, BMSCs, Osteoblast, Adipocyte, Paracrine factors, osteoblast differentiation

\section{Background}

Bone marrow-derived mesenchymal stem cells (BMSCs, also known as bone marrow skeletal stem cells) reside in the perivascular compartment of bone marrow and can differentiate into osteoblast and adipocyte cell lineages among other mesoderm cell types [1,2]. BMSCs hold a

\section{Correspondence: babdallah@health.sdu.dk}

${ }^{1}$ Molecular Endocrinology Laboratory (KMEB), Department of Endocrinology,

Odense University Hospital and University of Southern Denmark, Odense, Denmark

${ }^{2}$ Department of Biological Sciences, College of Science, King Faisal University,

Hofuf, Saudi Arabia

Full list of author information is available at the end of the article great promise in cell-based therapy for many degenerative diseases including osteoporosis, due to their differentiation potential, immune-modulatory functions and the secretion of paracrine factors involved in endogenous tissue regenerative capacity $[3,4]$.

Lineage-specific differentiation of BMSCs into either osteoblasts or adipocytes is regulated by many paracrine factors including cytokines/growth factors and hormones that act to induce intercellular signaling and subsequently activate the key transcriptional factors, core-binding factor 1 (CBFA1/Runx2) [5], or peroxisome proliferator-activated 
receptor gamma 2 (PPAR 2 ) [6] for osteogenesis and adipogenesis respectively.

Adipocytes-secreted adipokines and free fatty acids affect both osteoblasts and osteoclasts formation/activity and therefore mediate skeletal homeostasis [7, 8]. Marrow fat volume was observed to be increased in animal models of ovariectomy, aging and calorie restriction and in human, it was inversely correlated with BMD in the clinical conditions of aging, post-menopause, and anorexia nervosa (for review, [9-14]. Several studies attributed this increased marrow adiposity to the shifting in the differentiation capacity of BMSCs towards adipocyte versus osteoblast cell lineage, suggesting an inverse relationship between these two lineages [10, 15-17]. In vitro and in vivo studies reported a paracrine regulatory mechanism for controlling this inverse relationship between osteoblast and adipocyte differentiation of BMSCs $[7,9,10]$. For examples: adipocytes secrete factors that inhibit osteoblastogenesis and favor adipogenesis, such as sFRP-1 [18], sFRP-4, and chemerin [19] and proinflammatory cytokines [20].

To answer the question whether increased marrow adipocytes is one of the main contributing factor to reduce osteoblast differentiation and bone formation in osteoporosis, we aimed in this study to investigate the impact of adipocyte-secreted factors on BMSCs proliferation and osteoblast differentiation. Thus, we studied the paracrine effect of the serum free condition medium collected from stromal ST2 cell line-derived adipocytes (CM-Adipo) on the cell proliferation and differentiation of murine BMSCs. Results showed the inhibitory effect of adipocyte-secreted factors on the differentiation of mBMSCs into osteoblastic cell lineage without affecting their proliferation. Interestingly, CM-Adipo was found to block BMP2-induced osteogenesis via activating the inflammatory NF- $\mathrm{BB}$ pathway.

\section{Methods \\ Cell culture}

Mouse stromal cells ST2 was obtained from Leibniz Institute DSMZ-German Collection of Microorganisms and Cell Cultures (ACC 333, Braunschweig, Germany). Cells were cultured in DMEM supplemented with $10 \%$ fetal bovine serum (FBS) and 1\% penicillin/streptomycin $(\mathrm{P} / \mathrm{S})$ (all purchased from Gibco Invitrogen, USA).

Mouse BMSCs were isolated from wild-type 8-weeksold male C57BL/6 J mice as previously described [21]. In brief, the ends of mouse tibia and femur were cut and placed in special adapted Eppendorf tubes, centrifuged for $1 \mathrm{~min}$ at $400 \mathrm{~g}$ to collect the marrow cells. Cell were filtrated through a 70- $\mu \mathrm{m}$ nylon mesh filter and cultured in $175 \mathrm{~cm}^{2}$ flasks in RPMI-1640 medium supplemented with 12\% FBS (Gibco Invitrogen, USA), $12 \mu \mathrm{M}$ L-glutamine (Invitrogen) and 1\% penicillin/streptomycin (P/S)
(Gibco Invitrogen, USA). Non-adherent cells were removed after $24 \mathrm{~h}$ by washing with PBS, and adding $30 \mathrm{ml}$ of fresh medium. Every 3 to 4 day, cells were washed, and fresh medium was added for a period of 4 weeks. After 4 weeks, cells were washed and trypsinized.

The NF- $\kappa B$ inhibitor, BAY11-7082, that inhibits $\mathrm{I} \kappa \mathrm{B} \alpha$ [inhibitor of NF- $\kappa B$ (nuclear factor $\kappa B$ ) $\alpha$ ] phosphorylation in cells [22] and insulin were from Sigma-Aldrich ApS (Brondby, Denmark). Bone morphogenetic protein2 (BMP2), recombinant PDGF-BB and recombinant murine WNT-3a were purchased from PeproTech (London, UK). The concentrations of different growth factors were selected as previously describe [23-25], or based on manual instructions.

\section{Collection of conditioned medium (CM)}

ST2 cells and primary isolated murine BMSCs were induced to differentiate into adipocytes for 12 days as described below. To avoid any influence from the adipogenic inducer factors (i.e 1-methyl-3-isobutylxanthine (IBMX), dexamethasone and insulin) in the collected $\mathrm{CM}$, medium was changed with serum free DMEM containing $1 \% \mathrm{P} / \mathrm{S}$, and the adipocyte-derived $\mathrm{CM}(\mathrm{CM}$ Adipo) was collected after $24 \mathrm{~h}$. Serum free control CM (CM-Control) was collected from un-differentiated ST2 cells that cultured for 12 days in basal culture medium. Collected CM was centrifuged for $10 \mathrm{~min}$ at $1000 \mathrm{rpm}$ and aliquoted into small aliquots for different experiments. Based on the experimental setting, the serum free CM was used at either $100 \%$ or diluted with DMEM at $25 \%$ or $50 \%$. FBS and other osteogenic inducers were added freshly to the $\mathrm{CM}$ upon studying the effect of CM-Adipo on osteogenesis of mBMSCs. CM-Adipo obtained from ST2 cells-derived adipocytes was used throughout this study, except otherwise stated.

\section{Cell proliferation study}

Short-term in vitro cell growth was determined by culturing the cells at 2000 cells/well in 4 well plates in either CM-Adipo (100\%) or CM-control (100\%) supplemented with $2 \%$ FBS. Cells were trypsinized and counted by the hemocytometer.

\section{Real time-polymerase chain reaction (RT-PCR)}

RNA was extracted using TRIzol according to the manufacturer's instructions (Invitrogen) and the first strand cDNA was synthesized from $1 \mu \mathrm{g}$ of total RNA using a Revert $\operatorname{Aid}^{\text {sx }} \mathrm{H}$ minus first strand cDNA synthesis kit (Fermentas, St Leon-Rot, Germany). RT-qPCR was performed using an ABI StepOne ${ }^{\mathrm{mm}}$ Real-TIME PCR machine (Life Technologies/Applied Biosystems) with using Fast SYBR $^{\circ}$ Green Master Mix (Applied Biosystems, California, USA). The targeted primers and reference genes are shown in Additional file 1: Table S1. The data 
were normalized to the geometric means of the reference genes $\beta$-actin and HPRT. The relative expression levels of each target gene were calculated using a comparative CT method $\left[\left(1 /\left(2_{\mathrm{T}}^{\Delta \mathrm{C}}\right)\right.\right.$ formula, where $\Delta \mathrm{C}_{\mathrm{T}}$ is the difference between $\mathrm{C}_{\mathrm{T}}$-target and $\mathrm{C}_{\mathrm{T}}$-reference] with Microsoft Excel $2007^{\circ}$.

\section{PCR array analysis}

Total RNA was extracted from mBMSCs induced to osteoblast differentiation in either CM-Control or CMAdipo. Osteogenic $\mathrm{RT}^{2}$ Profiler ${ }^{\mathrm{ru}}$ PCR array, containing 84 osteoblast-related genes (Qiagen Nordic), was performed for each sample in triplicates using $\mathrm{SYBR}^{\circ}$ Green quantitative PCR method on Applied Biosystems 7500 real-time PCR system and data were analyzed according to the manufacturer's instructions.

\section{Adipocyte differentiation}

Cells were plated at 15,000 cells $/ \mathrm{cm}^{2}$ and cultured for 12 days in adipogenic-induction medium (AIM; DMEM supplemented with $9 \%$ horse serum, $450 \mu \mathrm{M}$ 1-methyl3-isobutylxanthine (IBMX), 100nM dexamethasone, $5 \mu \mathrm{g} / \mathrm{mL}$ insulin (Sigma-Aldrich) and $1 \mu \mathrm{M}$ rosiglitazone (BRL 49653, Cayman Chemical, Ann Arbor, Michigan). The media was changed every three days.

\section{Osteoblast differentiation}

Osteoblast differentiation was performed in cells plated at $10,000 / \mathrm{cm}^{2}$ in osteoblast-induction media (OIM) containing DMEM supplemented with 10\% FBS $10 \mathrm{mM}$ beta glycerophosphate (Calbiochem-Merck, Germany), $50 \mu \mathrm{g} / \mathrm{mL}$ L-ascorbic acid-2-phosphate (Wako Chemicals $\mathrm{GmbH}$, Germany) and $10 \mathrm{nM}$ dexamethasone (Sigma-Aldrich, Denmark). The medium was changed every three days during induction period.

\section{Alkaline phosphatase (ALP) activity and quantification} ALP activity was performed after 6 days of osteoblastic induction. Cell viability was determined using the Cell Titer-Blue cell viability assay according to the manufacturer's instructions (Promega, USA) and the viability measured at $560_{\mathrm{Ex}} / 590_{\mathrm{Em}} \mathrm{nm}$ using a FLUO star Omega plate reader (BMG Laboratories). ALP activity was determined following incubation with $1 \mathrm{mg} / \mathrm{ml}$ of P-nitro phenyl phosphate in $50 \mathrm{mMNAHCO}_{3}$ and $1 \mathrm{mM} \mathrm{MgCl}$ buffer (pH 9.6) at $37{ }^{\circ} \mathrm{C}$ for $20 \mathrm{~min}$. The activity was stopped by addition of $3 \mathrm{M} \mathrm{NaOH}$. The reaction absorbance was measured at $405 \mathrm{~nm}$ using a FLUO star Omega plate reader and ALP activity corrected for cell viability.

\section{Alkaline phosphatase (ALP) staining}

After 6 days of osteoblast differentiation, cells were fixed with acetone $/ 10 \mathrm{mM}$ citrate buffer $\mathrm{pH} 4.2$ (1.5:1 ratio) at room temperature for $5 \mathrm{~min}$ and incubated for $1 \mathrm{~h}$ at room temperature with ALP substrate staining solution containing $0.2 \mathrm{mg} / \mathrm{ml}$ Naphtol-AS-TR-phosphate dissolved in distilled water (1:5) and $0.417 \mathrm{mg} / \mathrm{ml}$ Fast Red dissolved in $0.1 \mathrm{M}$ Tris buffer.

\section{Oil Red $\mathrm{O}$ staining and quantification}

At day 12 of adipocyte induction, cells were fixed in 4\% paraformaldehyde for $10 \mathrm{~min}$ at room temperature and then stained with Oil Red O (0.5 g in 100\% isopropanol) (Sigma, USA). Lipid accumulations were quantified by elution of Oil Red O in absolute isopropanol for $10 \mathrm{~min}$ at room temperature. The absorbance of the extracted dye was detected at $490 \mathrm{~nm}$.

\section{Alizarin Red S staining and quantification}

Calcium deposition, at day 12 of osteoblastic differentiation, was measured using Alizarin Red staining. Osteoblasts were fixed with $70 \%$ ice-cold ethanol for $1 \mathrm{~h}$ at $-20{ }^{\circ} \mathrm{C}$ before addition of AR-S (40 mM; Sigma-Aldrich) dissolved in distilled water, $\mathrm{pH}$ 4.17. The cells were stained for $10 \mathrm{~min}$ at room temperature. The level of calcium deposition was quantified by elution of AR-S following incubation in 10\% cetylpyridinium chloride (Sigma-Aldrich) for $1 \mathrm{~h}$ at room temperature. The absorbance of the eluted dye was assessed at $570 \mathrm{~nm}$ in a FLU Ostar Omega plate reader.

\section{Western blot assays}

Cells were collected at specific time points post treatment, and washed in cold PBS buffer before being lysed in cell lysis buffer supplemented with protease inhibitor cocktail (Roche Diagnostics, Mannheim, Germany). Twenty $\mu \mathrm{g}$ of protein was separated on 8 to $12 \%$ NuPAGE $^{\bullet}$ Novex $^{\circ}$ Bis-Tris gel systems (Invitrogen). The membrane was blocked and probed with antibodies and incubated with peroxidase-conjugated secondary antibody (Santa Cruz Biotechnology, Aarhus, Denmark). Antibodies for (total or phosphor) specific Smad1/5/8 and NF-kB p65 were obtained from Cell Signaling Technology (Leiden, Netherland).

\section{Luciferase reporter assay}

The activation of NF- $\mathrm{KB}$ pathway was determined by using Cignal $^{\mathrm{Tw}}$ NF- $\mathrm{kB}$ luciferase Reporter Assay Kit (QIAGEN Ltd., Manchester, UK). HEK 293 or mBMSCs cells were cultured in 96-well plates and transfected with a mixture of NF- $\kappa B$ luciferase reporter negative control or positive control, along with Renilla construct (as an internal control) using Lipofectamine 2000 (Invitrogen) according to the manufacturer's instructions. After $24 \mathrm{~h}$, medium was changed with either CM-Adipo or CMControl and cells were cultured for $24 \mathrm{~h}$. Luciferase activities were determined using the Dual-Luciferase Assay System (Promega, Southampton, UK). Reporter activities 
were represented as arbitrary units after normalization to the internal Renilla reporter.

\section{Statistical analysis}

All experiments were performed in 3-6 replicates and in at least 3 independent experiments. The data were presented as the mean $\pm \mathrm{SD}$. Students $t$-test was used for comparison between two groups. Differences were considered statistically significant at ${ }^{*} P<0.05$, and ${ }^{* *} P<0.005$.

\section{Results}

\section{CM-Adipo does not affect the cell viability or cell proliferation of $\mathrm{mBMSCs}$}

We aimed to use the adipocyte-derived CM to examine the paracrine effect of adipocytes on mBMSCs proliferation and differentiation. For that purpose, the mouse stromal cell line ST2 was induced to differentiate into adipocytes for 12 days. As shown in Fig. 1a, more than $90 \%$ of ST2 cells were differentiated into adipocytes after
12 days of induction as assessed by Oil Red $\mathrm{O}$ staining and its quantification. In addition, the increased adipocytes formation in ST2 cells was associated with the significant upregulation of the mRNA expression of the early (Ppary2 and C/ebpo) and late (aP2, Apm1, Lpl) adipocytic markers (Fig. 1b). We then, studied the effect of serum free collected CM-Adipo versus CM-Control on both cell viability and cell proliferation of primary mBMSCs. Neither cell viability (measured by Cell TiterBlue) nor cell proliferation (measured by cell number) of mBMSCs was affected upon their culture for 12 days in CM-Adipo compared to CM-control (Fig. 1c\&d).

\section{CM-Adipo inhibits the differentiation of mBMSCs into osteoblastic cell lineage}

As shown in Fig. 2a\&b, CM-Adipo exerted dosedependent inhibitory effect on the osteogenesis of mBMSCs compared to CM-Control as assessed by quantitative ALP activity and matrix mineralization. Similarly, CM-Adipo obtained from primary mBMSCs-derived

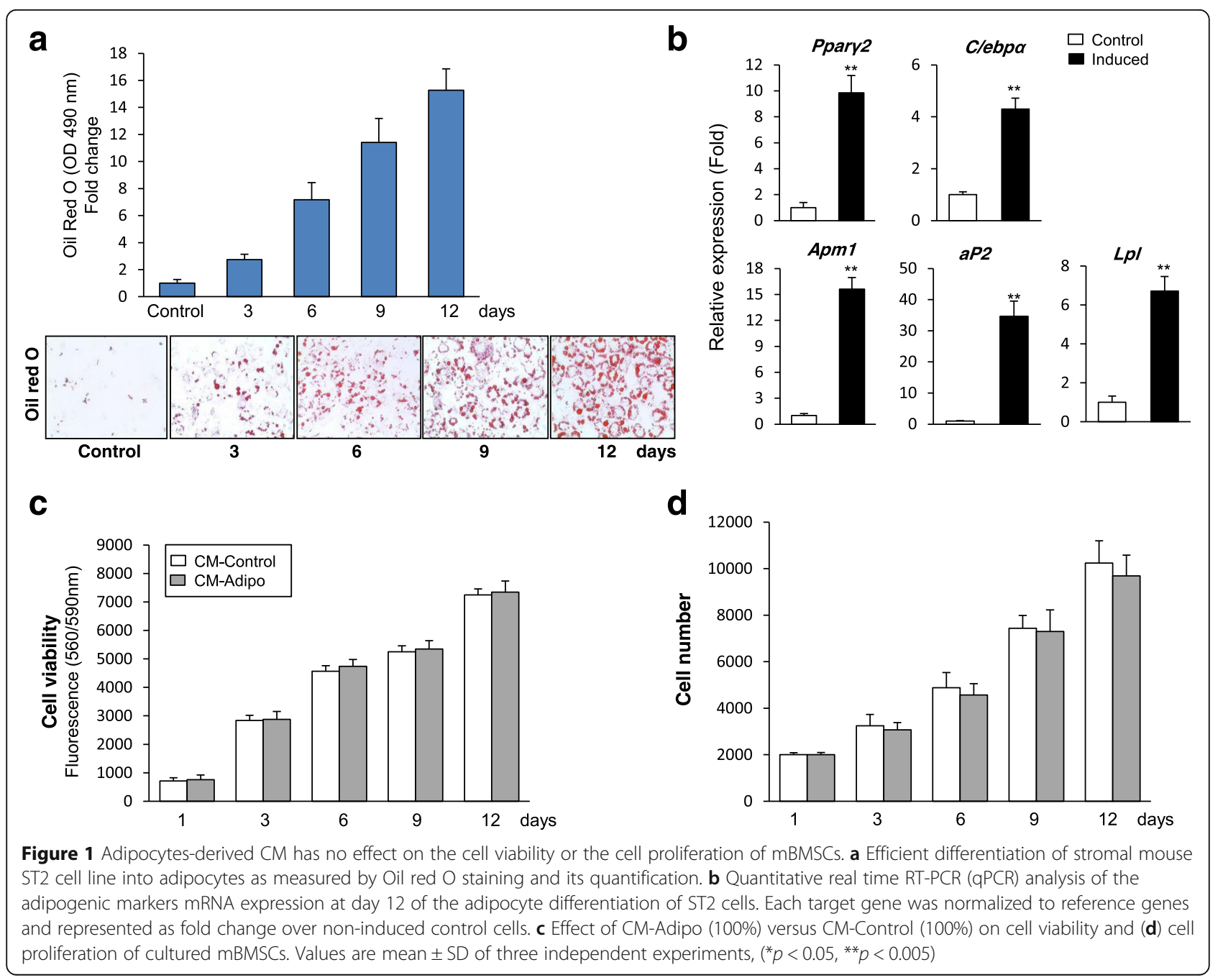




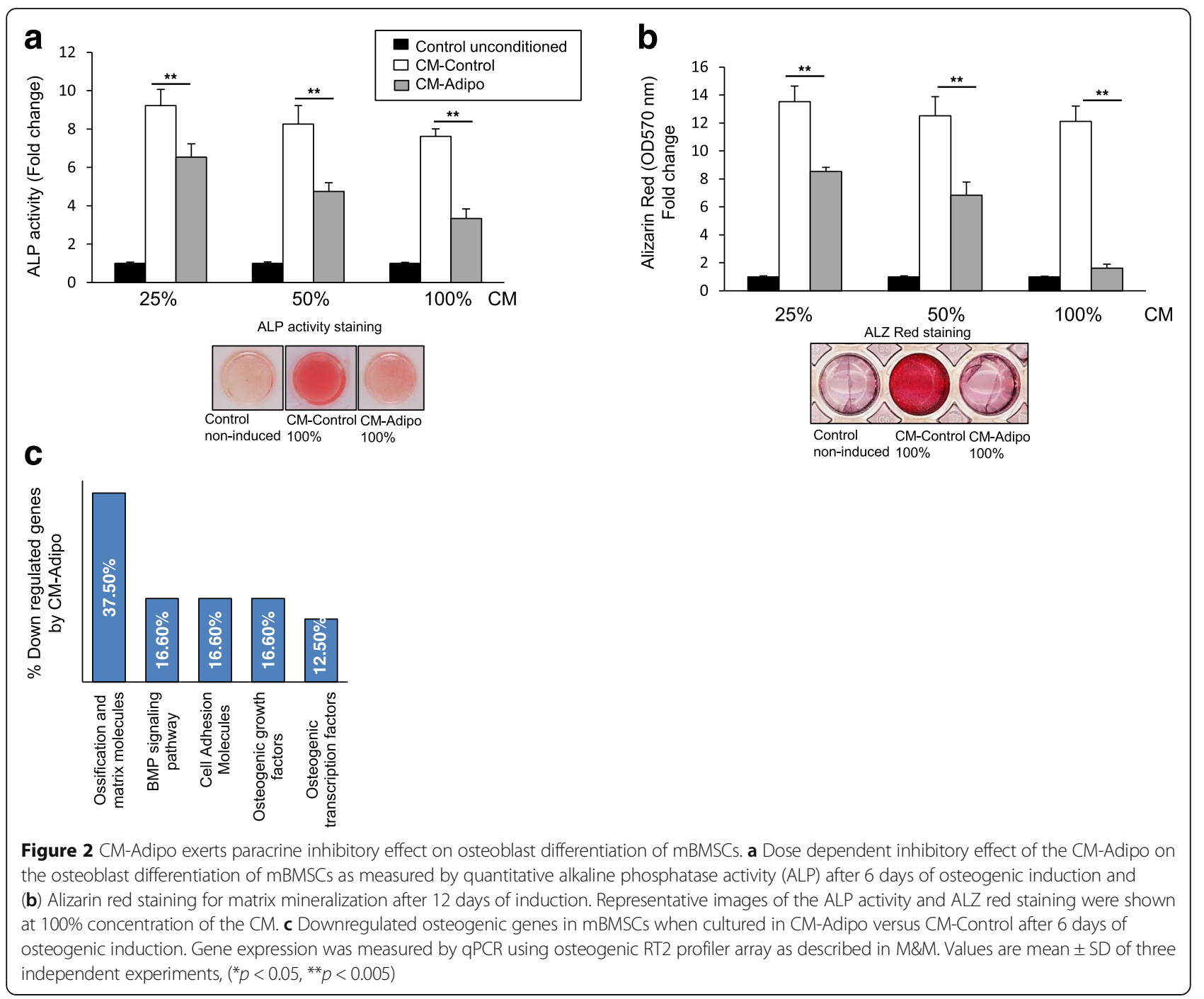

adipocytes showed dose-dependent inhibitory effect on ALP activity and matrix mineralization of mBMSCs during their induction into osteoblast differentiation (Additional file 2: Figure S1, A\&B). Furthermore, CMAdipo down-regulated 76.4\% ( $\geq 2$ fold, $p<0.05$ ) of the differentially expressed osteoblastic genes during mBMSCs differentiation compared to CM-Control as measured by real time PCR-based osteogenic gene array analysis (Fig. 2c, Table 1). The down-regulated genes by CM-Adipo included, the key osteogenic transcriptional factors; Run $x 2$ and $S p 7$ and factors involved in osteoblast differentiation and matrix mineralization, Alp, Col1a1, Ocn and integrins. We also examined the effect of CMAdipo on the expression of the adipocytic markers of mBMSCs. As shown in Additional file 2: Figure S2, CMAdipo did not affect the adipogenic markers of mBMSCs during their adipogenic differentiation induction as assessed by qPCR. These data support the paracrine inhibitory effect of adipocytes on osteoblast differentiate of mBMSCs, without affecting their switch between osteoblast/adipocyte differentiations.

\section{CM-Adipo inhibits BMP2-induced osteoblast differentiation of mBMSCs}

To get insight into the mechanism underlying the inhibitory effect of CM-adipo on osteoblast differentiation in bone marrow, we examined the inhibitory effect of CMAdipo on different signaling molecules known to induce osteogenesis in mBMSCs. Interestingly, CM-Adipo showed to significantly inhibit BMP2-induced ALP activity in mBMSCs by $77.5 \%$, while the inhibitory effects on the ALP activity of other osteogenic factors including PDGF, Wnt3a and insulin were $38.5,44.15$ and $41.7 \%$ respectively (Fig. 3a). In consistent, the CM-Adipo significantly inhibited the BMP2-induced matrix mineralization in mBMSCs in dose dependent manner (Fig. 3b). Furthermore, CM- 
Table 1 Down-regulation of osteogenic genes expression in mBMSCs treated with CM-Adipo as compared to CM-Control

\begin{tabular}{|c|c|c|}
\hline Gene name & $\begin{array}{l}\text { Gene } \\
\text { symbol }\end{array}$ & $\begin{array}{l}\text { Fold } \\
\text { change }\end{array}$ \\
\hline \multicolumn{3}{|l|}{ Ossification and matrix molecules } \\
\hline Alkaline phosphatase, liver/bone/kidney & Alpl & -6.8 \\
\hline Bone gamma carboxyglutamate protein & Bglap & -3.2 \\
\hline Biglycan & Bgn & -4.5 \\
\hline Cadherin 11 & Cdh11 & -5.0 \\
\hline Chordin & Chrd & -4.3 \\
\hline Collagen type I alpha 1 & Colla1 & -4.2 \\
\hline Collagen type I alpha 2 & Colla2 & -2.4 \\
\hline Collagen type $\mathrm{V}$ alpha 1 & Col5ar & -5.5 \\
\hline Secreted phosphoprotein 1 (Osteopontin) & Spp 1 & -5.8 \\
\hline \multicolumn{3}{|l|}{ BMP signaling pathway } \\
\hline Bone morphogenetic protein 2 & Bmp2 & -6.8 \\
\hline Bone morphogenetic protein 7 & Bmp7 & -3.1 \\
\hline Bone morphogenetic protein receptor. type $1 \mathrm{~A}$ & Bmpria & -4.5 \\
\hline MAD homolog 5 (Drosophila) & Smad5 & -3.2 \\
\hline \multicolumn{3}{|l|}{ Cell Adhesion Molecules } \\
\hline Fibronectin 1 & Fn1 & -6.2 \\
\hline Integrin beta 1 (fibronectin receptor beta) & $\operatorname{ltg} b 1$ & -2.1 \\
\hline Integrin alpha 2 & $\operatorname{ltg} a 2$ & -3.7 \\
\hline Integrin alpha $2 \mathrm{~b}$ & $\operatorname{ltg} a 2 b$ & -3.1 \\
\hline \multicolumn{3}{|l|}{ Osteogenic growth factors } \\
\hline Fibroblast growth factor receptor 2 & Fgfr2 & -2.6 \\
\hline Insulin-like growth factor 1 & $\operatorname{lgf1}$ & -9.2 \\
\hline Insulin-like growth factor I receptor & $\operatorname{lgfir}$ & -4.1 \\
\hline Platelet derived growth factor. alpha & Pdgfa & -2.9 \\
\hline \multicolumn{3}{|l|}{ Osteogenic transcription factors } \\
\hline Distal-less homeobox 5 & $D / x 5$ & -7.7 \\
\hline Runt related transcription factor 2 & Runx2 & -6.2 \\
\hline Sp7 transcription factor 7 & $S p 7$ & -4.3 \\
\hline
\end{tabular}

Cells were cultured in either $100 \%$ CM-Adipo or CM-Control and induced to differentiate into osteoblasts as described in the Methods. Mouse osteogenesis $\mathrm{RT}^{2}$ Profiler $^{\mathrm{TM}}$ PCR array with 84 osteoblast genes was performed for each CDNA sample using the SYBR ${ }^{\oplus}$ Green quantitative PCR method. Each target gene was normalized to reference genes and the differentially down-regulated genes by BMSCs in CM-Adipo were represented as fold change in the Table. Values are mean of three independent experiments

Adipo down-regulated the mRNA expression of BMP2induced osteoblastic markers including Runx2, Msx2, Dlx5,Ocn, Col1a1 and Alp in mBMSCs as measured by qPCR analysis (Fig. 3c). Western blot analysis of BMP2 signaling revealed the impairment of the BMP2induced Smad1/5/8 phosphorylation in mBMSCs upon treatment with CM-Adipo compared to CM-Control (Fig. 3d). These results demonstrated the paracrine inhibitory effect of adipocytes on BMPs signaling-induced osteogenesis in BMSCs.
The inhibitory effect of CM-Adipo on BMP2-induced osteogenesis is mediated by NF-KB activation

Since NF- $\mathrm{KB}$ signaling was found to inhibit BMP2induced osteoblast differentiation [26], we hypothesized that the activation of NF- $\mathrm{kB}$ signaling by adipokines [27] is a plausible mechanism that mediating the inhibitory effect of CM-Adipo on BMP2-induced osteogenesis. Thus, we first examined whether NF- $\mathrm{BB}$ signaling pathway is activated in mBMSCs by CM-Adipo. Interestingly, western blot analysis showed the stimulation of the NF$\kappa \mathrm{B}$ subunit p-65 phosphorylation in mBMSCs treated with CM-Adipo compared with CM-Control (Fig. 4a). Furthermore, CM-Adipo significantly stimulated the NF$\mathrm{\kappa B}$ reporter luciferase activity by 2.7 and 4.15 folds at 50 and $100 \%$ concentrations respectively as compared to CM-Control (Fig. 4b). Also, the same stimulatory effect of CM-Adipo on NF- $\mathrm{KB}$ reporter luciferase activity was obtained in transfected mBMSCs (Additional file 2: Figure S3, A). We then examined the effect of the potent NF- $\mathrm{kB}$ inhibitor, BAY 11-7082 (an irreversible inhibitor of $\mathrm{IKK} \alpha$ ) on rescuing the inhibitory effect of CM-Adipo on BMP2-induced ALP activity in BMSCs. As shown in Fig. 4c\&d, BAY11-7082 significantly retrieved the inhibitory effect of CM-Adipo on BMP2-induced ALP activity and matrix mineralization in mBMSCs by 2.6 and 2.3 folds respectively. These data suggested that the inhibitory effect of CM-Adipo on BMP-induced osteogenesis is at least in part mediated via activating the $N F-\kappa B$ signaling.

\section{Discussion}

In this study, we demonstrated the paracrine inhibitory effect of marrow adipocytes on the differentiation potential of mBMSCs into osteoblasts by blocking BMP2-induced osteogenesis. This effect is mediated via a mechanism involved the activation of the NF- $\mathrm{B} B$ signaling pathway by adipokines.

In this study, the ST2 cell line [28] was selected as a source of adipocytes for collecting the CM-Adipo due to the following reasons; a) ST2 cell line is a clone of homogenous stromal cell population that derived from the mouse bone marrow with a characteristics phenotype of pre-adipocytic cells; b) ST2 cells can efficiently differentiate into homogenous population of adipocytes; c) ST2 cells are suitable for collecting the serum free conditioned medium due to their ability to maintain their viability in serum free medium for up to $48 \mathrm{~h}$.

To avoid any undesirable effects from the residual amount of adipogenic inducers (i.e Dexamethasone, IBMX and insulin) in the collected CM, we changed the adipogenic medium with serum and adipogenic inducers free medium prior to the collection of CM. This strategy eliminated the plausible competing effects between such adipogenic inducers (exist at relatively high concentrations) and 


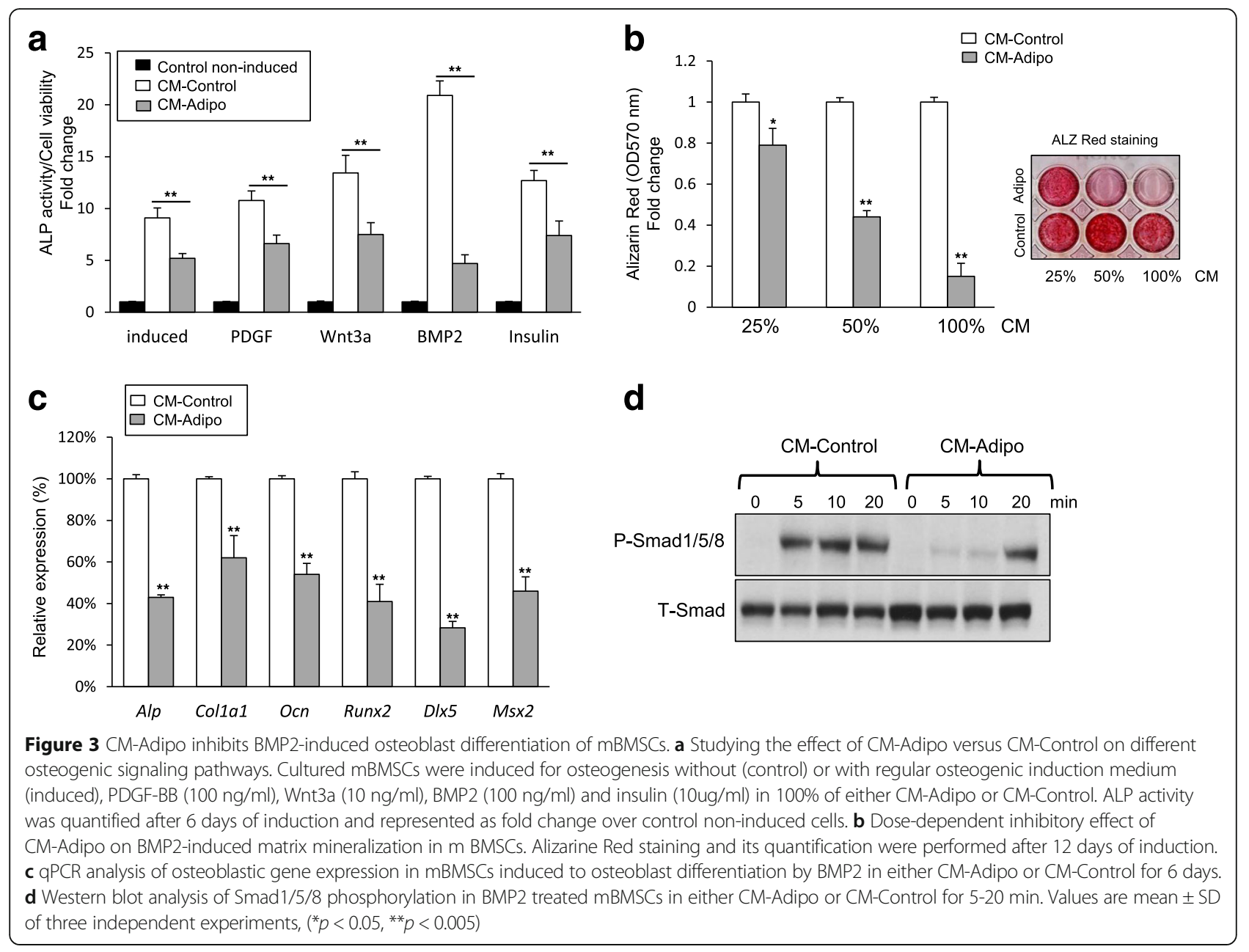

the adipocytes-secreted factors (exist at low concentrations) on the osteoblast differentiation of mBMSCs. In supporting to this notion, the high concentration of dexamethasone-induced adipogenic differentiation of BMSCs was reported to suppress the proliferation of osteoblasts [29].

Our data demonstrated the paracrine inhibitory effect of CM-Adipo on osteoblast differentiation of mBMSCs. Few studies have investigated the paracrine effect of adipocytes on osteoblast differentiation. For example, Benayahu et al. [30] demonstrated the inhibitory effect of adipocyte CM on osteogenesis of marrow-derived osteoblastic cells, MBA-15, while Maxson S, et al., [31] showed the stimulatory effect of adipocyte $\mathrm{CM}$ on the osteoblast differentiation of BMSCs. On the other hand, mammary adipose tissue-derived CM did not affect osteoblast differentiation of primary human osteoblasts [32]. These contradictory data can be attributed to the use of different sources of adipocytes for collecting CM. In addition, these studies apply the traditional method for collecting CM, which does not exclude the presence of adipogenic inducers. Indeed, when such inducers were omitted in a co-culture system, adipocytes were shown not only to inhibit osteoblast differentiation of BMSCs [33, 34] but also to induce their trans-differentiation into adipocytes [35].

Our data identified the BMPs signaling as the most distinct osteogenic pathway to be inhibited by the adipocytes CM. In consistence with our finding, the impairment of BMPs signaling was reported in BMSCs derived from osteoporotic postmenopausal women (the condition of increased marrow adipocytes) [36]. Recently, the activation of NF-kB was shown to suppress the BMP2-induced osteogenesis. In this mechanism, the inflammatory environment-stimulated NF- $\mathrm{kB}$ activity suppresses BMPs pathway via either activating the Toll-like receptor- 4 and its intracellular adaptor protein My88 (TLR4/MyD88) dependent pathway [26] or interfering with DNA binding of the Smad complex $[37,38]$. The interaction between BMPs and NF- $\mathrm{kB}$ signaling pathways was further confirmed by demonstrating that the inhibition of local inflammation is effective to promote the BMP-2 induced bone regeneration in vivo $[39,40]$. Considering, that the adipocytes secret several inflammatory cytokines including IL-6, TNF-a, IL-1 $\beta$, MCP1, CCL2 and PAI-1 known to be 


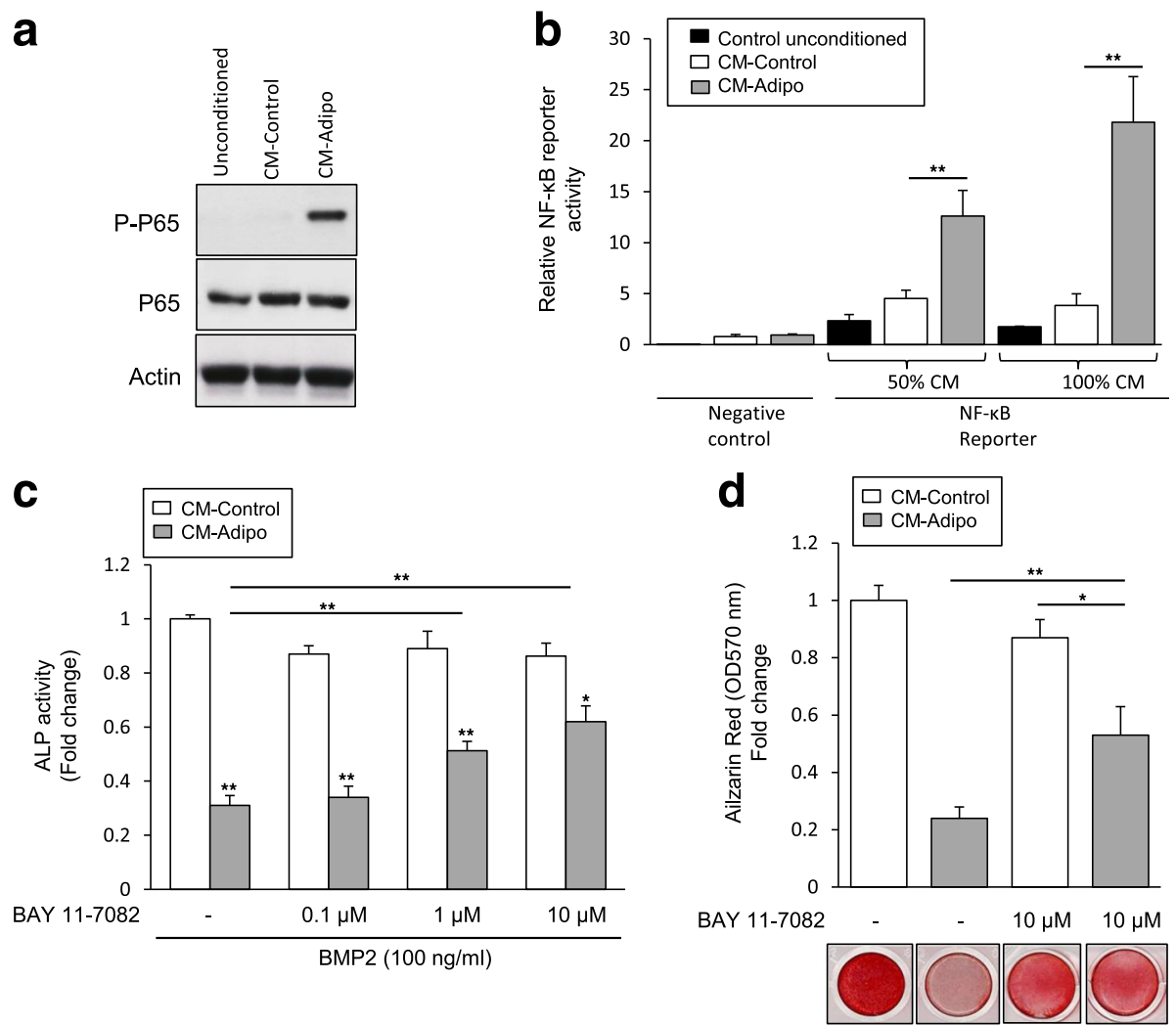

Figure 4 The inhibitory effect of CM-Adipo on BMP2-induced osteogenesis is mediated by activating NF-kB signaling pathway. b Western blot analysis of NF-KB subunit p-65 phosphorylation in mBMSCs cultured in CM-Adipo versus CM-Control. Cells were incubated with the CM for $30 \mathrm{~min}$ and cell laystes were subjected to western blot analysis. b CM-Adipo stimulates NF-kB signaling activity. HEK 293 cells were transfected with Cignal NF-KB Reporter negative control, or positive control. Cells were incubated with 50\% and 100\% CM-Control or CM-Adipo for $24 \mathrm{~h}$. Dual-luciferase assays were performed, and reporter activity was represented as arbitrary units after normalization to the internal Renilla reporter. c Effect of NF-kb inhibitor, BAY 11-7082 on retrieving the inhibition of BMP2-induced osteoblast differentiation, as measured by ALP activity quantification and (d) Alizarin Red staining of matrix mineralization. Cells were treated with different concentrations of the inhibitor, $1 \mathrm{~h}$ prior the treatment with BMP2. ALP activity was measured after 6 days and represented as fold change after normalization to the cell viability. Alizarin Red was measured after 10 days. Values are mean \pm SD of three independent experiments, $\left({ }^{*} p<0.05,{ }^{* *} p<0.005\right)$

involved in the activation of the NF-kB [27, 41], our data demonstrated the stimulatory effect of CM-Adipo on the $\mathrm{NF}-\mathrm{kB}$ signaling activation. In addition, we showed that the blocking of NF- $\mathrm{kB}$ signaling in mBMSCs rescued the inhibitory effect of CM-Adipo on BMP2-induced osteogenesis, suggesting that the inhibitory effect of CM-Adipo on osteoblast differentiation is mediated at least in part by NF- $\mathrm{kB}$ activation. Taken together, the inhibitory effect of CM-Adipocyte on osteogenesis is mediated by a group of secreted factors (Adipokines) rather than one individual factor and targeting the inhibition of adipocyte differentiation could be beneficiary for enhancing bone formation

\section{Conclusions}

Marrow adiposity is inversely correlated with bone mass in many osteoporotic clinical conditions. The differentiation potential of BMSCs into either osteoblastic or adipocytic cell lineage was shown to be regulated by local and secreted factors in bone marrow microenvironment. Here, we studied the paracrine effect of adipocytes on the differentiation capacity of mBMSCs into osteoblasts. Our data demonstrated the paracrine inhibitory effect of adipocytes-secreted factors on the osteoblast differentiation of mBMSCs by blocking BMPs signaling in a mechanism mediated by the activation of NF- $\mathrm{kB}$ pathway. This study identified a novel mechanism that controlling the paracrine inhibitory effect of adipocytes on osteoblast differentiation of BMSCs.

\section{Additional files}

Additional file 1: Table S1. List of primers used for qRT-PCR. (PDF 638 kb)

Additional file 2: Figure S1. CM-Adipo obtained from mBMSCs-derived adipocytes exerts paracrine inhibitory effect on osteoblast differentiation of mBMSCs. Figure S2. CM-Adipo does not affect the the adipogenic markers expression in mBMSCs. Figure S3. The stimulatory effect of CM-Adipo on NF-kb signaling pathway in mBMSCs. (PDF 937 kb) 


\section{Abbreviations}

ALP: Alkaline phosphatase; aP2: Adipocyte lipid-binding protein 2; APM1: Adiponectin; BMP: Bone morphogenetic protein; C/EBP-a: CCAAT/ enhancer-binding protein alpha; Col1a1: Collagen type 1; LPL: Lipoprotein lipase; NF-kB: Nuclear factor kappa-light-chain-enhancer of activated B cells; OCN: Osteocalcin; OPN: Osteopontin; PPARY2: Peroxisome proliferatoractivated receptor gamma 2; Runx2: Runt-related transcription factor 2; SFRP: Secreted Frizzled-Related Protein 4

\section{Acknowledgments}

Professor Moustapha Kassem is thanked for providing the research facilities at KMEB laboratory, OUH, Denmark to perform some of the experiments of this study. The author is grateful to Bianca Jørgensen and Catherine Reilly for excellent technical assistance.

\section{Funding}

This work was funded by Novo Nordisk Foundation, Denmark (R152-A12355).

\section{Availability of data and materials}

All materials are available by the corresponding author

\section{Authors' contributions}

BMA conceived the project, designed the study, performed experiments, analyzed data and wrote the manuscript.

\section{Competing interests}

The author declares that he has no competing interests.

\section{Consent for publication}

Not applicable.

\section{Ethics approval and consent to participate}

Not applicable.

\section{Author details}

${ }^{1}$ Molecular Endocrinology Laboratory (KMEB), Department of Endocrinology, Odense University Hospital and University of Southern Denmark, Odense, Denmark. 2Department of Biological Sciences, College of Science, King Faisal University, Hofuf, Saudi Arabia. ${ }^{3}$ Faculty of Science, Helwan University, Cairo, Egypt.

Received: 13 October 2016 Accepted: 31 January 2017

\section{Published online: 07 February 2017}

\section{References}

1. Abdallah BM, Kassem M. Human mesenchymal stem cells: from basic biology to clinical applications. Gene Ther. 2008;15:109-16.

2. Bianco P, Robey PG. Skeletal stem cells. Development. 2015;142:1023-7.

3. Burchfield JS, Dimmeler S. Role of paracrine factors in stem and progenitor cell mediated cardiac repair and tissue fibrosis. Fibrogenesis Tissue Repair. 2008;1:4.

4. Pigott JH, Ishihara A, Wellman ML, Russell DS, Bertone AL. Investigation of the immune response to autologous, allogeneic, and xenogeneic mesenchymal stem cells after intra-articular injection in horses. Vet Immuno Immunopathol. 2013;156:99-106.

5. Komori T, Yagi H, Nomura S, Yamaguchi A, Sasaki K, Deguchi K, Shimizu Y, Bronson RT, Gao YH, Inada M, Sato M, Okamoto R, Kitamura Y, Yoshiki S, Kishimoto T. Targeted disruption of Cbfa1 results in a complete lack of bone formation owing to maturational arrest of osteoblasts. Cell. 1997;89:755-64.

6. Siersbæk R, Nielsen R, Mandrup S. Transcriptional networks and chromatin remodeling controlling adipogenesis. Trends Endocrinol Metab. 2012;23:56-64

7. Sadie-Van Gijsen H, Crowther NJ, Hough FS, Ferris WF. The interrelationship between bone and fat: from cellular see-saw to endocrine reciprocity. Cell Mol Life Sci. 2013;70:2331-49.

8. Sheu Y, Cauley JA. The Role of Bone Marrow and Visceral Fat on Bone Metabolism. Curr Osteoporos Rep. 2011;9:67-75.

9. Hardouin P, Pansini V, Cortet B. Bone marrow fat. Joint Bone Spine. 2014;81:313-9

10. Abdallah BM, Kassem M. New factors controlling the balance between osteoblastogenesis and adipogenesis. Bone. 2012;50:540-5.
11. Bredella MA, Fazeli PK, Daley SM, Miller KK, Rosen CJ, Klibanski A, Torriani M. Marrow fat composition in anorexia nervosa. Bone. 2014;66:199-204.

12. Grey A, Beckley V, Doyle A, Fenwick S, Horne A, Gamble G, Bolland M. Pioglitazone increases bone marrow fat in type 2 diabetes: results from a randomized controlled trial. Eur J Endocrinol. 2012;166:1087-91.

13. Schwartz AV. Marrow Fat and Bone: Review of Clinical Findings. Front Endocrinol. 2015;6:40.

14. Schwartz AV, Sigurdsson S, Hue TF, Lang TF, Harris TB, Rosen CJ, Vittinghoff E, Siggeirsdottir K, Sigurdsson G, Oskarsdottir D, Shet K, Palermo L, Gudnason V, Li X. Vertebral Bone Marrow Fat Associated With Lower Trabecular BMD and Prevalent Vertebral Fracture in Older Adults. J Clin Endocrinol Metab. 2013;98:2294-300.

15. Berendsen AD, Olsen BR. Osteoblast-Adipocyte Lineage Plasticity in Tissue Development, Maintenance and Pathology. Cell Mol Life Sci. 2014;71:493-7.

16. Hardouin P, Rharass T, Lucas S. Bone Marrow Adipose Tissue: To Be or Not To Be a Typical Adipose Tissue? Front Endocrinol. 2016;7:85

17. Li J, Liu X, Zuo B, Zhang L. The Role of Bone Marrow Microenvironment in Governing the Balance between Osteoblastogenesis and Adipogenesis. Aging Dis. 2016;7:514-25.

18. Taipaleenmaki H, Abdallah BM, Aldahmash A, Saamanen AM, Kassem M. Wnt signalling mediates the cross-talk between bone marrow derived preadipocytic and pre-osteoblastic cell populations. Exp Cell Res. 2011;317:745-56.

19. Muruganandan S, Roman AA, Sinal CJ. Role of chemerin/CMKLR1 signaling in adipogenesis and osteoblastogenesis of bone marrow stem cells. J Bone Miner Res. 2010;25:222-34.

20. Shapses SA, Sukumar D. Bone Metabolism in Obesity and Weight Loss. Annu Rev Nutr. 2012;32:287-309.

21. Peister A, Mellad JA, Larson BL, Hall BM, Gibson LF, Prockop DJ. Adult stem cells from bone marrow (MSCs) isolated from different strains of inbred mice vary in surface epitopes, rates of proliferation, and differentiation potential. Blood. 2004;103:1662-8.

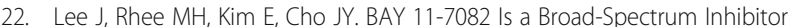
with Anti-Inflammatory Activity against Multiple Targets. Mediators Inflamm 2012;2012:416036.

23. Abdallah BM, Ditzel N, Laborda J, Karsenty G, Kassem M. DLK1 Regulates Whole-Body Glucose Metabolism: A Negative Feedback Regulation of the Osteocalcin-Insulin Loop. Diabetes. 2015;64:3069-80.

24. Andersen RK, Zaher W, Larsen KH, Ditzel N, Drews K, Wruck W, Adjaye J, Abdallah BM, Kassem M. Association between in vivo bone formation and ex vivo migratory capacity of human bone marrow stromal cells. Stem Cell Res Ther. 2015;6:196.

25. Zeng Z, Yin X, Zhang X, Jing DA, Feng XUE. Cyclic stretch enhances bone morphogenetic protein-2-induced osteoblastic differentiation through the inhibition of Hey1. Int J Mol Med. 2015;36:1273-81.

26. Huang R-L, Yuan Y, Zou G-M, Liu G, Tu J, Li Q. LPS-Stimulated Inflammatory Environment Inhibits BMP-2-Induced Osteoblastic Differentiation Through Crosstalk Between TLR4/MyD88/NF-kB and BMP/Smad Signaling. Stem Cells Dev. 2014;23:277-89.

27. Mancuso P. The role of adipokines in chronic inflammation. Immunotargets Ther. 2016;5:47-56.

28. Ogawa M, Nishikawa S, Ikuta K, Yamamura F, Naito M, Takahashi K, Nishikawa S. $B$ cell ontogeny in murine embryo studied by a culture system with the monolayer of a stromal cell clone, ST2: B cell progenitor develops first in the embryonal body rather than in the yolk sac. EMBO J. 1998;7:1337-43.

29. Walsh S, Jordan GR, Jefferiss C, Stewart K Beresford JN. High concentrations of dexamethasone suppress the proliferation but not the differentiation or further maturation of human osteoblast precursors in vitro: relevance to glucocorticoid-induced osteoporosis. Rheumatology. 2001;40:74-83.

30. Benayahu D, Zipori D, Wientroub S. Marrow Adipocytes Regulate Growth and Differentiation of Osteoblasts. Biochem Biophys Res Commun. 1993;197:1245-52

31. Maxson S, Burg KJL. Conditioned media cause increases in select osteogenic and adipogenic differentiation markers in mesenchymal stem cell cultures. J Tissue Eng Regen Med. 2008:2:147-54.

32. Maurin AC, Chavassieux PM, Frappart L, Delmas PD, Serre CM, Meunier PJ Influence of mature adipocytes on osteoblast proliferation in human primary cocultures. Bone. 2000;26:485-9.

33. Zhang H, Lu W, Zhao Y, Rong P, Cao R, Gu W, Xiao J, Miao D, Lappe J, Recker R, Xiao GG. Adipocytes Derived from Human Bone Marrow Mesenchymal Stem Cells Exert Inhibitory Effects on Osteoblastogenesis. Curr Mol Med. 2011;11:489-502. 
34. Liu L-F, Shen W-J, Zhang ZH, Wang LJ, Kraemer FB. Adipocytes decrease Runx2 expression in osteoblastic cells: Roles of PPARy and adiponectin. J Cell Physiol. 2010;225:837-45.

35. Clabaut A, Delplace S, Chauveau C, Hardouin P, Broux O. Human osteoblasts derived from mesenchymal stem cells express adipogenic markers upon coculture with bone marrow adipocytes. Differentiation. 2010;80:40-5.

36. Donoso O, Pino AM, Seitz G, Osses N, Rodríguez JP. Osteoporosis-associated alteration in the signalling status of BMP-2 in human MSCs under adipogenic conditions. J Cell Biochem. 2015;116:1267-77.

37. Hirata-Tsuchiya S, Fukushima H, Katagiri T, Ohte S, Shin M, Nagano K, Aoki K, Morotomi T, Sugiyama G, Nakatomi C, Kokabu S, Doi T, Takeuchi H, Ohya K, Terashita M, Hirata M, Kitamura C, Jimi E. Inhibition of BMP2-Induced Bone Formation by the p65 Subunit of NF-KB via an Interaction With Smad4. Mol Endocrinol. 2014;28:1460-70.

38. Yamazaki M, Fukushima H, Shin M, Katagiri T, Doi T, Takahashi T, Jimi E. Tumor Necrosis Factor a Represses Bone Morphogenetic Protein (BMP) Signaling by Interfering with the DNA Binding of Smads through the Activation of NF-KB. J Biol Chem. 2009;284:35987-95.

39. Ratanavaraporn J, Furuya H, Tabata Y. Local suppression of proinflammatory cytokines and the effects in BMP-2-induced bone regeneration. Biomaterials. 2012;33:304-16.

40. Lee K-B, Murray SS, Taghavi CE, Song K-J, Brochmann EJ, Johnson JS, Keorochana G, Liao J-C, Wang JC. Bone morphogenetic protein binding peptide reduces the inflammatory response to recombinant human bone morphogenetic protein-2 and recombinant human bone morphogenetic protein-7 in a rodent model of soft-tissue inflammation. Spine J. 2013;11:568-76.

41. Schäffler A, Müller-Ladner U, Schölmerich J, Büchler C. Role of Adipose Tissue as an Inflammatory Organ in Human Diseases. Endocr Rev. 2006:27:449-67.

\section{Submit your next manuscript to BioMed Central} and we will help you at every step:

- We accept pre-submission inquiries

- Our selector tool helps you to find the most relevant journal

- We provide round the clock customer support

- Convenient online submission

- Thorough peer review

- Inclusion in PubMed and all major indexing services

- Maximum visibility for your research

Submit your manuscript at www biomedcentral.com/submit

\section{( BioMed Central}

